\title{
Contribuição à avaliação ambiental de materiais e componentes construtivos: proposta de método para obtenção de extrato lixiviado
}

\author{
Contribution to the environmental assessment of \\ construction components: proposal of method for \\ obtaining the lixiviated extract
}

\section{Marlova Piva Kulakowski \\ Feliciane Andrade Brehm \\ Claudio de Souza Kazmierczak \\ Mariele Lunkes}

\section{Resumo}

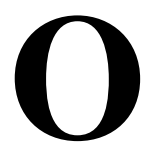

s materiais de construção civil estão sujeitos à lixiviação de seus constituintes, que podem levar à contaminação do ambiente. No Brasil, a avaliação ambiental de materiais e componentes com resíduos é realizada por análise do extrato lixiviado, empregando-se os mesmos métodos e parâmetros destinados a resíduos, em amostras sólidas fragmentadas, que não reproduzem a forma de exposição a que o componente é submetido. O presente trabalho propõe e discute a viabilidade de dois métodos de ensaio para a obtenção do extrato lixiviado para avaliação ambiental de materiais e componentes construtivos: um por imersão, simulado um cenário de exposição de intenso e prolongado contato com o lixiviante, como um alagamento; e outro por irrigação, que busca simular uma exposição à chuva ácida. Como corpo de prova, é proposto o emprego de placas com dimensões de 25x200x400 mm, e, como meio lixiviante, uma solução de ácido nítrico ajustada para $\mathrm{pH} 3,0 \pm 0,05$. O período total de ensaio de cada um dos métodos compreende 28 dias, em ciclos de 7dias. A coleta do extrato lixiviado ocorre ao final de cada ciclo. Os primeiros testes empregaram cerâmica vermelha, com e sem a óxido de cromo. Após quatro ciclos de 7 dias de exposição, foi possível observar tendência à estabilização na concentração de $\mathrm{Cr}$ no extrato lixiviado, o que corrobora a viabilidade do experimento em 4 semanas.

Palavras-chaves: Avaliação ambiental. Lixiviação. Métodos de ensaio. Cerâmica vermelha. Cromo.

Marlova Piva Kulakowski Universidade do Vale do Rio dos Sinos São Leopoldo - RS - Brasil

Feliciane Andrade Brehm Universidade do Vale do Rio dos Sinos São Leopoldo - RS - Brasil

Claudio de Souza Kazmierczak Universidade do Vale do Rio dos Sinos São Leopoldo - RS - Brasil

Mariele Lunkes Insituto Pró-Universidade Canoense Porto Alegre - RS - Brasil

Recebido em 18/03/14 Aceito em 17/10/14

\section{Abstract}

The building materials are subject to lixiviation, which can lead to environmental contamination. In Brazil, the environmental assessment of building materials and components with waste is carried out employing the same methods and parameters used to evaluate waste, in small solid samples, which do not reproduce the type of exposure the component is subject to. This paper proposes and discusses the feasibility of two testing methods to obtain the leached extract for the environmental assessment of building materials and components: one by immersion, which simulates a scenario of intense and prolonged exposure to the leaching solution, as in flooding; and another one by irrigation in order to simulate exposure to acid rain. It was proposed plates measuring $25 \times 200 \times 400 \mathrm{~mm}$ as test specimens. The leaching solution was a nitric acid with $\mathrm{pH} 3.0 \pm 0.05$. Fired-clay test samples with and without the addition of chrome oxide were produced. The testes were conducted in four 7-day cycles. The leached extracts were collected at the end of each cycle samples. After each one of four 7-day exposure cycles it was possible to observe a tendency to stabilization in the concentration of $\mathrm{Cr}$ in the leached extract, which corroborates the feasibility of the experiment in a twenty-eight days period.

Keywords: Environmental assessment. Lixiviation. Test methods. Red ceramic. Chrome. 


\section{Introdução}

Os avanços no uso de resíduos sólidos como fontes de matéria-prima na construção civil têm permitido, cada vez mais, reverter futuros passivos ambientais em produtos com valor agregado, de forma a reduzir custos e prejuízos ambientais relativos à disposição final, além de minimizar os impactos ambientais decorrentes da extração de matérias-primas diretamente do meio ambiente. Essa tendência mundial está fazendo crescer a indústria da reciclagem, que, por sua vez, demanda pesquisas e estudos que avaliem e garantam o processo de reaproveitamento e/ou reciclagem dos resíduos em todos os aspectos, desde o técnico, passando pelo econômico até o de segurança ambiental.

Vários aspectos vinculados à avaliação ambiental de materiais de construção civil que incorporam resíduos necessitam ser discutidos de forma mais sistematizada no meio técnico nacional. Sloot (1997) afirma que a avaliação ambiental de um resíduo estabilizado por solidificação $(\mathrm{E} / \mathrm{S}) \mathrm{em}$ determinada matriz (argamassa, concreto, cerâmica, etc.) requer o ensaio de lixiviação de materiais e resíduos. Tais ensaios são fundamentais, pois podem prever a liberação, em longo prazo, de substâncias que podem ser impactantes ao meio ambiente, contaminando solos e recursos hídricos. Os materiais de construção civil ditos convencionais, produzidos com matérias-primas oriundas de recursos naturais, raramente são caracterizados sob esse aspecto. Em se tratando de resíduos de construção e demolição (RCD), muitos textos os definem genericamente como inertes, e na Resolução Conama 307 existe apenas a classificação de Classe D para resíduos perigosos, devendo ser direcionados para aterros próprios para disposição final. A mesma resolução estabelece ainda que "Aterro de resíduos classe A de reservação de material para usos futuros: é a área tecnicamente adequada onde serão empregadas técnicas de destinação de resíduos da construção civil classe A no solo", sendo considerados resíduos classe A aqueles oriundos de concreto, argamassa, alvenaria, escavações, entre outros, com características próprias para reciclagem como agregados. A forma como é recomendada a reservação do resíduo classe $\mathrm{A}$ induz à interpretação de que essa resolução esteja classificando-os como Classe II-B: não perigosos inertes. No entanto, estudos recentes (BREHM et al., 2013) apresentam resultados de que tanto a cerâmica vermelha quanto o concreto podem solubilizar Fe e Al acima dos limites admitidos pela NBR 10004 (ABNT, 2004b), o que os classificaria como resíduo Classe II-A, não perigoso, não inerte. Dessa forma, se forem tomados ainda como referência os limites de lixiviação e solubilização da NBR 10004 (ABNT, 2004b), como parâmetros para classificação ambiental de materiais e componentes, não somente os materiais e componentes de construção civil alternativos que incorporam resíduos devem ser avaliados ambientalmente, mas também aqueles tradicionalmente empregados.

$\mathrm{Na}$ Holanda, segundo Eikelboom, Ruwiel e Goumans (2001), a preocupação com o impacto ambiental dos materiais de construção civil resultou na especificação do Decreto Holandês para Materiais de Construção, implementado em 1999, onde não é feita nenhuma diferenciação quanto à origem dos materiais, sejam eles produzidos a partir de matérias-primas naturais ou oriundos de coprodutos e resíduos. A aplicação dos requisitos estabelecidos por esse decreto é destinada aos materiais de construção empregados em elementos que estejam em contato com solos e fonte d'água ou expostos à ação direta da intempérie, como, por exemplo, em aterros, estradas, fundações, paredes externas e coberturas de edifícios. Para a implementação do decreto, foram necessários o desenvolvimento de padrões e a execução de um programa para criação e validação de métodos de ensaios e certificação. No Brasil, essa discussão ainda é incipiente. É necessário trazer para o escopo do ambiente construído discussões acerca do tema, de maneira a serem estabelecidos padrões e requisitos ambientais, métodos de ensaio e um sistema de certificação, e, a partir disso, elaborar uma recomendação técnica no âmbito do Sistema Nacional de Avaliação Técnica(Sinat).

Neste trabalho, faz-se uma discussão a respeito do método de ensaio de lixiviação. No setor da construção civil brasileira, ensaios de lixiviação são utilizados apenas quando se estuda a incorporação de resíduos em matrizes de materiais de construção, sendo empregado o método da NBR 10005 (ABNT, 2004a), destinado à avaliação ambiental de resíduos. Entretanto, o método da referida norma não se aproxima de uma situação de uso. A preparação da amostra é realizada fracionando-a até um tamanho de grãopassante na peneira de malha $9,5 \mathrm{~mm}$, o que aumenta drasticamente a superfície de contato com a solução lixiviante e elimina o efeito da porosidade do componente na velocidade de lixiviação, de forma a impedir que o resultado do ensaio seja extrapolado para uma situação real de lixiviação do componente construtivo.

Vollpracht e Brameshuber (2010) propõem a realização de uma simulação de cenários de 
exposição de elementos construtivos a partir do uso de prismas de materiais íntegros, mediante o emprego do material em situação real de uso. O método proposto por este trabalho, adaptado de Vollpracht e Brameshuber (2010), remete a dois cenários distintos de exposição: um teste de imersão, que simula em condições aceleradas uma condição de intenso e prolongado contato com o meio lixiviante, como, por exemplo, um alagamento; e um teste de irrigação, que busca simular uma exposição à chuva. Este trabalho integra um projeto de pesquisa mais amplo e tem por objetivo apresentar uma proposta de método de ensaio de obtenção de extrato lixiviado, ou de lixiviação, para fins de avaliação ambiental de materiais e componentes de construção civil.

\section{Referencial teórico}

\section{Terminologia}

Por se tratar de um tema multidisciplinar, apresentado no contexto do ambiente construído, se faz necessário, neste trabalho, esclarecer que a terminologia adotada é aquela estabelecida pelo conjunto de normas da ABNT, que classifica ambientalmente os resíduos. Os termos em destaque são apresentados a seguir com suas respectivas definições.

O termo lixiviação refere-se à capacidade de transferência de substâncias orgânicas e inorgânicas presentes no resíduo sólido, por meio de dissolução no meio extrator (ABNT, 2004a).

A norma define lixiviado como o extrato obtido a partir do ensaio de lixiviação (ABNT, 2004a).

A solubilização é a operação que tem o objetivo de diluir substâncias contidas nos resíduos, por meio de lavagem em meio aquoso. $\mathrm{Na} E / S$ a solubilização dos contaminantes é caracterizada por meio de sua transferência para o meio líquido, conforme a NBR 10006 (ABNT, 2004c).

A solução lixiviante é o fluido percolante utilizado em qualquer extração ou solubilização seletiva dos constituintes químicos de um material (ABNT, 2004a).

Com a finalidade de manter a clareza dos termos empregados neste trabalho, alguns dos termos acima conceituados merecem ser ressaltados, como é o caso da diferença entre os conceitos de lixiviação e solubilização. A extração dos constituintes químicos dos resíduos, embora não esteja explicitada no conceito de lixiviação estabelecido pela NBR 10005 (ABNT, 2004a), é obtida mediante o emprego de um fluido percolante com característica ácida, o que é apresentado no escopo da mesma norma. A mesma falta de clareza ocorre com o conceito de solubilização, pois norma brasileira não deixa explícito nele que a extração é realizada por meio de lavagem com água, e somente ao estabelecer o método é que se define o meio extrator.

$\mathrm{Na}$ literatura internacional é comum evidenciar o uso de água para os testes de lixiviação, como é o caso da norma francesa AFNOR XP X31-210 (ASSOCIATION..., 2012), porém cabe ressaltar que nesta pesquisa tratar-se-á da água como fluido percolante, e não solução lixiviante. Já lixiviação e seus termos derivados estão associados à extração de constituintes através de solução com característica ácida.

\section{Avaliação Ambiental}

Atualmente, para prever o impacto ambiental causado pela disposição de um resíduo ou de uma matriz contendo resíduo, são empregados testes de lixiviação. Há uma variada gama deles, que se diferem pelo $\mathrm{pH}$ da solução lixiviante, agitação do meio, formato da amostra, proporção da amostra e solução lixiviante, tempo de exposição, entre outros fatores.

\begin{abstract}
Alguns métodos buscam investigar o equilíbrio ou semiequilíbrio entre o resíduo e a solução lixiviante, outros forçam a percolação da solução, e há métodos que admitem que a solução lixiviante seja frequentemente renovada. Como consequência, John e Ângulo (2006) salientam que materiais que contêm resíduos são muitas vezes submetidos a testes que não se aproximam das condições reais, aquelas às quais o material será submetido durante seu ciclo de vida.
\end{abstract}

Normalmente, a escolha entre os vários tipos de testes de lixiviação é feita conjuntamente entre o órgão ambiental responsável e o gerador (CAUDURO; ROBERTO, 2002), e pode variar de país para país, conforme suas regulamentações. As regulamentações podem envolver normas ou protocolos. Os protocolos constituem-se de um conjunto de normas que levam em conta vários aspectos para avaliar os materiais, como integridade física, propriedades mecânicas e de lixiviação. Segundo Brito (2007), os principais documentos que são usados para avaliar materiais que incorporam resíduos são os protocolos do Canadá e da França e o modelo dos Estados Unidos, elaborados respectivamente pelas agências Waste Technology Center (WCT), Association Française de Normalization (AFNOR) e United States Environmental Protection Agency (U.S. EPA). No Brasil, não é utilizado um protocolo para avaliação ambiental de um produto que incorpore resíduo ou da estabilização por solidificação (E/S) de contaminantes. Essa 
avaliação é feita a partir de normas vigentes no país. Segundo Gomes (2006), a norma brasileira de lixiviação, a NBR 10005 (ABNT, 2004a), assim como o método americano 1311 TCLP (UNITED..., 1992), tem o propósito de classificar um resíduo de forma simples, reprodutível e com baixo custo. Ambos os procedimentos estabelecem que $100 \mathrm{~g}$ de amostra com granulometria menor que $9,5 \mathrm{~mm}$ permaneçam durante $18 \mathrm{~h}$ em contato com uma solução ácida, sob agitação, em uma proporção de amostra/solução lixiviante de 1:20. Após esse período, o lixiviado é filtrado e analisado.

A maioria dos testes de lixiviação utilizados para caracterização ambiental de resíduos ou de produtos E/S consideram condições de disposição final em aterro, e para isso utilizam a amostra fracionada, como é o caso do teste descrito no método 1311 TCLP (UNITED..., 1992) e na norma brasileira NBR 10005 (ABNT, 2004a). Poucos são os testes que utilizam amostras não fracionadas, ou seja, na forma íntegra, como é o caso do teste de lixiviação descrito na norma americana ANS 16.1 (AMERICAN..., 2003).

O objetivo da norma ANS 16.1 é a determinação da lixiviabilidade de resíduos radioativos solidificados. Esta norma foi desenvolvida para uso em um bloco sólido, não podendo ser empregada para materiais pulverizados ou na forma de pequenas partículas (AMERICAN..., 2003). Um grande diferencial do teste da norma ANS 16.1 é que ela permite realizar uma previsão da perda de poluentes, ao longo do tempo, através de um cálculo acurado da área superficial do corpo de prova na forma íntegra, de modo que a difusibilidade possa ser determinada. Neste teste, uma amostra de resíduo solidificado é enxaguada em água desmineralizada. Após o enxágue de $30 \mathrm{~s}$, a amostra é deixada em repouso em um recipiente com característica não reativa (usualmente vidro) por intervalos de tempo específicos. A água desmineralizada é renovada após cada extração.

Existem ainda outros testes de lixiviação descritos em normas americanas, como os testes da norma Multiple Extraction Procedure (MEP) e Extraction Procedure (EP). De forma resumida, destacam-se a seguir os testes utilizados por países como a Holanda, a França e a Alemanha para caracterização ambiental de resíduos.

Na Alemanha, a norma DIN 38144-4 (DEUTSCHES..., 1984) é utilizada tanto para a classificação de resíduos quanto para produtos da E/S, denominados pela norma de monólitos. No teste, a amostra é utilizada com granulometria menor que $10 \mathrm{~mm}$, sendo exposta à água destilada durante 24 h sob agitação (DEUTSCHES..., 1984).
Segundo Brito e Soares (2009), a França possui uma norma de lixiviação muito utilizada para avaliação de produtos da E/S. A norma NF X 31211 (ASSOCIATION..., 2012) faz parte do protocolo francês de avaliação ambiental de materiais E/S. O ensaio prevê o uso de três corpos de prova, os quais devem ser confeccionados nas dimensões $4 \times 4 \times 8 \mathrm{~cm}$ e testados mediante agitação mecânica com água desmineralizada. São recomendadas três extrações com duração de $16 \mathrm{~h}$ cada, e uma proporção de amostra/fluido percolante de 1:10 (ASSOCIATION..., 1998).

A norma de lixiviação NEN 7345 (NETHERLANDS..., 1995) é utilizada pela Holanda para avaliar resíduos que passaram pelo processo de E/S. Ela permite fazer uma avaliação do material solidificado em diferentes estágios, sem realizar a trituração da amostra solidificada, ou seja, na forma de corpo monolítico (NETHERLANDS ..., 1995). A norma recomenda que uma amostra com dimensões de $40 \times 40 \mathrm{~mm}^{2}$ seja imersa em uma solução lixiviante de $\mathrm{pH} 4,0$, com proporção de líquido de cinco vezes o peso da amostra, e seu extrato é avaliado em um período que varia entre 0,25 e 64 dias.

$\mathrm{Na}$ Tabela 1 é possível verificar as diferenças entre os procedimentos de lixiviação descritos nestas e em algumasoutras normas. Comparando-se os dados apresentados na Tabela 2, é possível observar que os métodos divergem entre si quanto à solução lixiviante, a relação amostra/líquido, o tempo de ensaio e a forma da amostra. Para fins de uma simulação mais agressiva, foi verificado que entre oito normas apresentadas cinco utilizam meio ácido com $\mathrm{pH}$ situado entre 3 e 5 , o que pode ser um indicador para a escolha da solução a ser adotada. Quatro normas empregam ciclos de extrações, sendo o mais longo de 64 dias, o que se considera excessivo.

A proposta para a avaliação de materiais e componentes de construção civil que incorporam resíduos é baseada nas normas abordadas, utilizando-se como premissas a facilidade e o tempo de execução para a obtenção dos extratos lixiviados. As questões relativas à montagem dos dispositivos e aos procedimentos necessários para a execução são compreendidas como "facilidade" dos testes previstos para o método. Por sua vez, a definição do tempo de execução não tem por intenção determinar que seja empregado o menor espaço de tempo, mas que sejam gerados resultados coerentes a partir de um tempo de ensaio aceitável pelo meio técnico da área, e que se aproxime dos já praticados em outros métodos voltados para avaliação de propriedades dos materiais e componentes de sistemas construtivos. 
Tabela 1 -Parâmetros para testes de lixiviação em algumas normas técnicas

\begin{tabular}{|c|c|c|c|c|}
\hline Norma de lixiviação & Meio líquido & $\begin{array}{c}\text { Relação } \\
\text { amostra/líquido }\end{array}$ & Período do teste & $\begin{array}{c}\text { Forma da } \\
\text { amostra } \\
\end{array}$ \\
\hline $\begin{array}{l}\text { Method } 1311 \text { TCLP } \\
\text { (UNITED..., 1992) }\end{array}$ & $\begin{array}{c}\text { Água destilada } \\
\text { com } \mathrm{pH}<5,0\end{array}$ & $1: 20$ & $18 \mathrm{~h}$ & $\begin{array}{l}\text { Triturada } \\
(9,5 \mathrm{~mm})\end{array}$ \\
\hline $\begin{array}{l}\text { NF X31-211 } \\
\text { (ASSOCIATION..., } \\
2012)\end{array}$ & $\begin{array}{c}\text { Água } \\
\text { desmineralizada }\end{array}$ & $1: 10$ & $\begin{array}{c}3 \text { extrações de } 16 \text { h } \\
\text { cada }\end{array}$ & $\begin{array}{l}\text { Bloco sólido } \\
\text { (monólito) }\end{array}$ \\
\hline $\begin{array}{l}\text { ANS 16.1 } \\
\text { (AMERICAN..., } \\
2003)\end{array}$ & $\begin{array}{c}\text { Água } \\
\text { desmineralizada }\end{array}$ & -- & $\begin{array}{c}\text { Enxague inicial de } \\
30 \mathrm{~s}+\text { série de } \\
\text { extrações }\end{array}$ & $\begin{array}{l}\text { Bloco sólido } \\
\text { (monólito) }\end{array}$ \\
\hline $\begin{array}{l}\text { Method } 1320 \text { MEP } \\
\text { (UNITED..., 1986) }\end{array}$ & $\begin{array}{l}\text { Solução ácida } \\
\text { pH 5,0 (24 h } \\
\text { iniciais) } \\
\text { Solução ácida } \\
\text { pH 3,0 (8 } \\
\text { extrações) }\end{array}$ & $\begin{array}{l}\text { 1:16 (24 h iniciais) } \\
1: 20 \text { (8 extrações })\end{array}$ & $\begin{array}{l}\text { Extração inicial de } \\
24 \text { h }+8 \text { extrações } \\
\text { de } 24 \text { h cada }\end{array}$ & -- \\
\hline $\begin{array}{l}\text { NEN } 7345 \\
\text { (NETHERLANDS ..., } \\
1995)\end{array}$ & $\begin{array}{l}\text { Solução ácida } \\
\text { pH 4,0 }\end{array}$ & $1: 5$ & 0,25 a 64 dias & $\begin{array}{l}\text { Bloco sólido } \\
\text { (monólito) }\end{array}$ \\
\hline $\begin{array}{l}\text { Method 1310B EP } \\
\text { (UNITED..., 2004) }\end{array}$ & $\begin{array}{c}\text { Solução ácida } \\
\text { pH 5,0 }\end{array}$ & $1: 20$ & $24 \mathrm{~h}$ & $\begin{array}{l}\text { Triturada } \\
(<9,5 \mathrm{~mm})\end{array}$ \\
\hline $\begin{array}{l}\text { DIN 38414-4 } \\
\text { (DEUTSCHES..., } \\
\text { 1984) }\end{array}$ & Da amostra & $1: 10$ & $24 \mathrm{~h}$ & $\begin{array}{l}\text { Triturada } \\
(<10 \mathrm{~mm})\end{array}$ \\
\hline $\begin{array}{l}\text { NBR } 10005 \text { (ABNT, } \\
2004 a)\end{array}$ & $\begin{array}{l}\text { Solução ácida } \\
\text { pH 5,0 }\end{array}$ & $1: 20$ & $18 \mathrm{~h}$ & $\begin{array}{l}\text { Triturada } \\
(<9,5 \mathrm{~mm})\end{array}$ \\
\hline
\end{tabular}

Tabela 2 - Concentrações médias de $\mathrm{Cr}$ total presente nos lixiviados das amostras sem e com incorporação de óxido de cromo (ppm)

\begin{tabular}{|c|c|c|c|c|c|c|c|c|c|c|}
\hline \multirow{2}{*}{\multicolumn{2}{|c|}{$\begin{array}{c}\text { Testes de } \\
\text { lixiviação }\end{array}$}} & \multicolumn{9}{|c|}{ Concentração de $\mathrm{Cr}$ (em ppm) verificado no lixiviado } \\
\hline & & $\begin{array}{c}1^{\circ} \text { Ciclo } \\
7 \text { dias } \\
\end{array}$ & $\begin{array}{c}\text { Desv. } \\
\text { padrão }\end{array}$ & $\begin{array}{l}2^{\circ} \text { Ciclo } \\
14 \text { dias }\end{array}$ & $\begin{array}{c}\text { Desv. } \\
\text { padrão }\end{array}$ & $\begin{array}{l}3^{\circ} \text { Ciclo } \\
21 \text { dias }\end{array}$ & $\begin{array}{c}\text { Desv. } \\
\text { padrão }\end{array}$ & $\begin{array}{l}4^{\circ} \text { Ciclo } \\
28 \text { dias } \\
\end{array}$ & $\begin{array}{c}\text { Desv. } \\
\text { padrão }\end{array}$ & Total $[\Sigma]$ \\
\hline \multirow{6}{*}{ 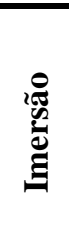 } & $\mathrm{CP0}$ & 0,022 & $\pm 0,002$ & 0,0049 & 0,000 & $\overline{n . d}$ & - & $\overline{\text { n.d }}$ & - & $\mathbf{0 , 0 2 4 9 3}$ \\
\hline & & 0,019 & & 0,0048 & & n.d & & n.d & & \\
\hline & & 0,019 & & 0,0049 & & n.d & & n.d & & \\
\hline & CP1 & 0,09900 & $\pm 0,001$ & 0,02200 & $\pm 0,002$ & 0,003 & $\pm 0,002$ & n.d & - & 0,12430 \\
\hline & & 0,10000 & & 0,02100 & & 0,0028 & & n.d & & \\
\hline & & 0,10100 & & 0,01900 & & 0,0031 & & n.d & & \\
\hline \multirow{6}{*}{ 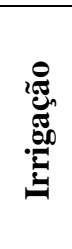 } & CP0 & n.d & - & 0,00081 & 0,000 & 0,00087 & $\pm 0,002$ & n.d & - & 0,00170 \\
\hline & & n.d & & 0,00084 & & 0,00085 & & n.d & & \\
\hline & & n.d & & 0,00082 & & 0,00087 & & n.d & & \\
\hline & CP1 & 0,00380 & 0,000 & 0,00478 & $\pm 0,001$ & 0,00273 & $\pm 0,001$ & 0,00043 & 0,000 & 0,01183 \\
\hline & & 0,00400 & & 0,00477 & & 0,00274 & & 0,00041 & & \\
\hline & & 0,00390 & & 0,00477 & & 0,00272 & & 0,00044 & & \\
\hline
\end{tabular}

\section{Materiais e métodos}

\section{Método para avaliação ambiental de componentes que incorporam resíduos}

Os testes propostos têm a finalidade de simular, de forma acelerada, uma condição real de exposição da amostra à chuva ou ao contato mais prolongado com uma solução ácida. No entanto, por se tratar de ensaios de laboratório, os sistemas foram construídos em uma escala reduzida, e a aceleração do processo ocorreu em função da concentração adotada do meio lixiviante e de exposição da amostra a ciclos de molhagem e secagem. Os ensaios de ambos os testes foram executados em sala climatizada, com temperatura de $23 \pm 1{ }^{\circ} \mathrm{C}$ e umidade relativa do ar de $70 \pm 5 \%$. Além disso, 
ambas as propostas de teste, num primeiro momento, foram estudadas empregando-se a mesma solução lixiviante, para fins de avaliação dos métodos em condições de aceleração iguais.

Corpo de prova - foi proposto o emprego de uma placa de dimensões de $20 \times 40 \times 25 \mathrm{~cm}$, de forma a atender a corpos de prova de diversos tipos de matrizes que incorporem resíduos e a oferecer uma superfície de exposição satisfatória.

Solução lixiviantes - a solução lixiviante, nesta etapa do projeto, compreendeu uma solução de $\mathrm{HNO}_{3}$ ajustada para $\mathrm{pH} 3,0 \pm 0,05$. Para cada teste foi empregado o mesmo volume de solução lixiviante de 11,2 L. Tomou-se como base para o dimensionamento desse volume o maior nível de precipitação $(140 \mathrm{~mm})$ registrado pelo Instituto de Meteorologia na estação de Porto Alegre nos últimos 50 anos.

Teste de imersão - este teste consiste na imersão de um corpo de prova em um reservatório preenchido com a solução lixiviante. Na Figura 1 é apresentada uma representação gráfica do recipiente de imersão e na Figura 2 são exemplificados ensaios com material cerâmico em andamento. $\mathrm{O}$ reservatório de vidro tem dimensões de $30 \mathrm{~cm}$ de largura, $50 \mathrm{~cm}$ de comprimento e 15 $\mathrm{cm}$ de altura. A espessura do vidro do reservatório é de $5 \mathrm{~mm}$. Compõem ainda o reservatório dois apoios de vidro posicionados no fundo. Os apoios, com as dimensões de $30 \mathrm{~cm}$ de comprimento e 5 $\mathrm{cm}$ de altura, encontram-se fixados paralelamente um ao outro, distanciados em $17 \mathrm{~cm}$, de modo a garantir que o corpo de prova não fique em contato direto com o fundo do reservatório e que esteja envolvido em todas as faces por um volume mínimo de solução. O reservatório possui ainda uma tampa de vidro (Figura 2).

Foram definidos 4 ciclos de 7 dias, totalizando um período de ensaio de 28 dias. Ao final de cada cicloo extrato lixiviado foi coletado em frascos devidamente preparados para acondicionar a amostra, encaminhada para análise de metais e para análise pela técnica Espectrometria de Emissão Atômica por Plasma Acoplado Indutivamente (ICP-AES). A cada novo ciclo a solução foi renovada.

Teste de irrigação - este procedimento compreende o gotejamento de uma solução lixiviante sobre um corpo de prova. A irrigação da solução lixiviante é realizada com uma vazão média de 7,8 $\mathrm{mL} / \mathrm{min}$. Para o teste de irrigação foi utilizado um reservatório de vidro com $30 \mathrm{~cm}$ de largura, $30 \mathrm{~cm}$ de comprimento e $77 \mathrm{~cm}$ de altura.
Na Figura 3 é possível observar o desenho do aparato que foi utilizado para esse teste. Empregou-se vidro de espessura de $5 \mathrm{~mm}$.Apoios de vidro com as dimensões de $20 \mathrm{~cm}$ de comprimento e $20 \mathrm{~cm}$ de altura encontram-se fixados paralelamente uns aos outros, no fundo do reservatório. Os apoios têm a função de manter o corpo de prova afastadodo volume de extrato lixiviado, reservado no fundo.Na parte superior do reservatório foi fixado horizontalmente um dispositivo de irrigação, composto de um cano de PVC de $5 \mathrm{~cm}$ de diâmetro e de $22 \mathrm{~cm}$ de comprimento, com as extremidades fechadas. Esse aparato tem como objetivo distribuir a solução lixiviante por meio de gotejamento, realizado através de orifícios de $2,5 \mathrm{~mm}$ de diâmetro, distribuídos em linha reta, com espaçamento de $1 \mathrm{~cm}$ entre eles. A alimentação do cano de PVC com asolução lixiviante se dá através de umaentrada de $1,5 \mathrm{~cm}$ de diâmetro.Compõe ainda o aparato do teste um reservatório (barrilete) de PVC com capacidade de $20 \mathrm{~L}$, para armazenar e abastecer, de forma contínua e com vazão constante, o sistema de irrigação com a solução lixiviante. A altura de posicionamento do barrilete em relação ao sistema de irrigação é de $20 \mathrm{~cm}$.

A molhagem e secagem do corpo de prova foi proposta em 4 ciclos, cada um compreendido por um período de $24 \mathrm{~h}$ de gotejamento da solução e um período de secagem de 6 dias, à temperatura ambiente, totalizando 28 dias de teste. A cada ciclo o lixiviado foi coletado e devidamente conservado para posterior análise. Os corpos de prova permanecem durante o período de molhagem do teste dispostos com uma inclinação de $45^{\circ}$. A Figura 4 apresenta $\mathrm{o}$ teste de lixiviação por irrigação em execução.

Controle do $\mathrm{pH}$ da solução lixiviante - o pH das soluções lixiviantes preparadas empregadas nos 4 ciclos foram de 3,04, 3,01, 2,97 e 3,00. É possível verificar que todas as soluções lixiviantes empregadas nos testes de imersão e irrigação apresentaram $\mathrm{pH}$ dentro do limite da variação preestabelecido, correspondente a 3,0 $\pm 0,05$.

Teste de lixiviação da NBR 10005 - para fins de análise dos testes de lixiviação do método proposto, corpos de prova foram submetidos à análise de lixiviação também pelo método da NBR 10005 (ABNT, 2004a), conduzida em laboratório que presta serviços de análises ambientais. Foram produzidas placas cerâmicas de mesma dimensão, que foram trituradas em fragmentos de dimensão de $9,5 \mathrm{~mm}$, de forma a atender à norma. 
Figura 1 - Dimensões do reservatório do teste de imersão

Figura 2 - Teste de imersão em execução
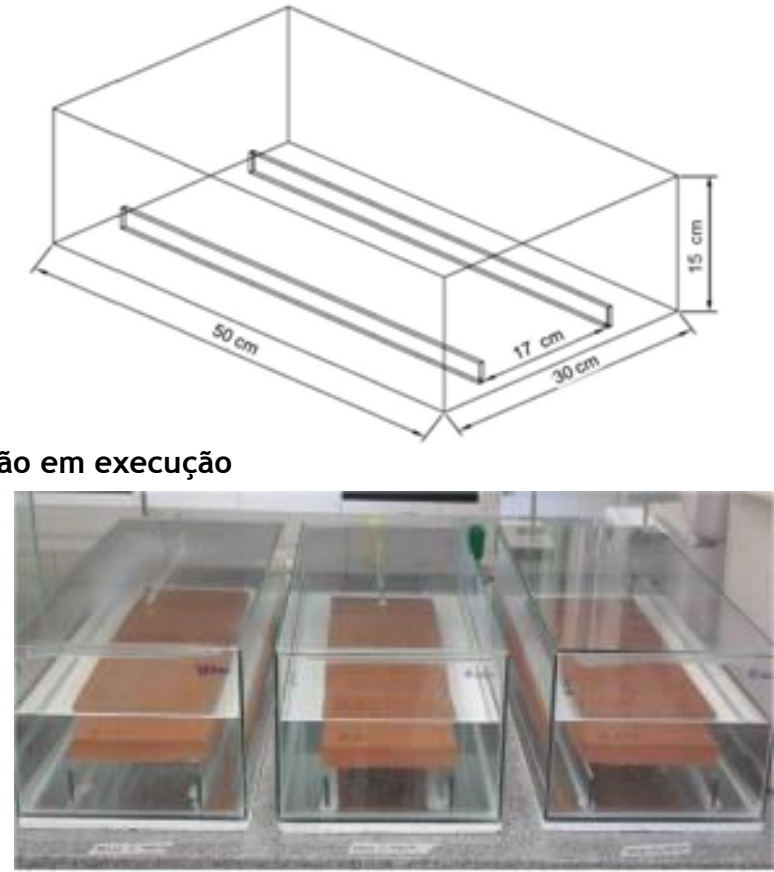

Figura 3 - Aparato para o teste de irrigação: (a) vista frontal e (b) vista lateral

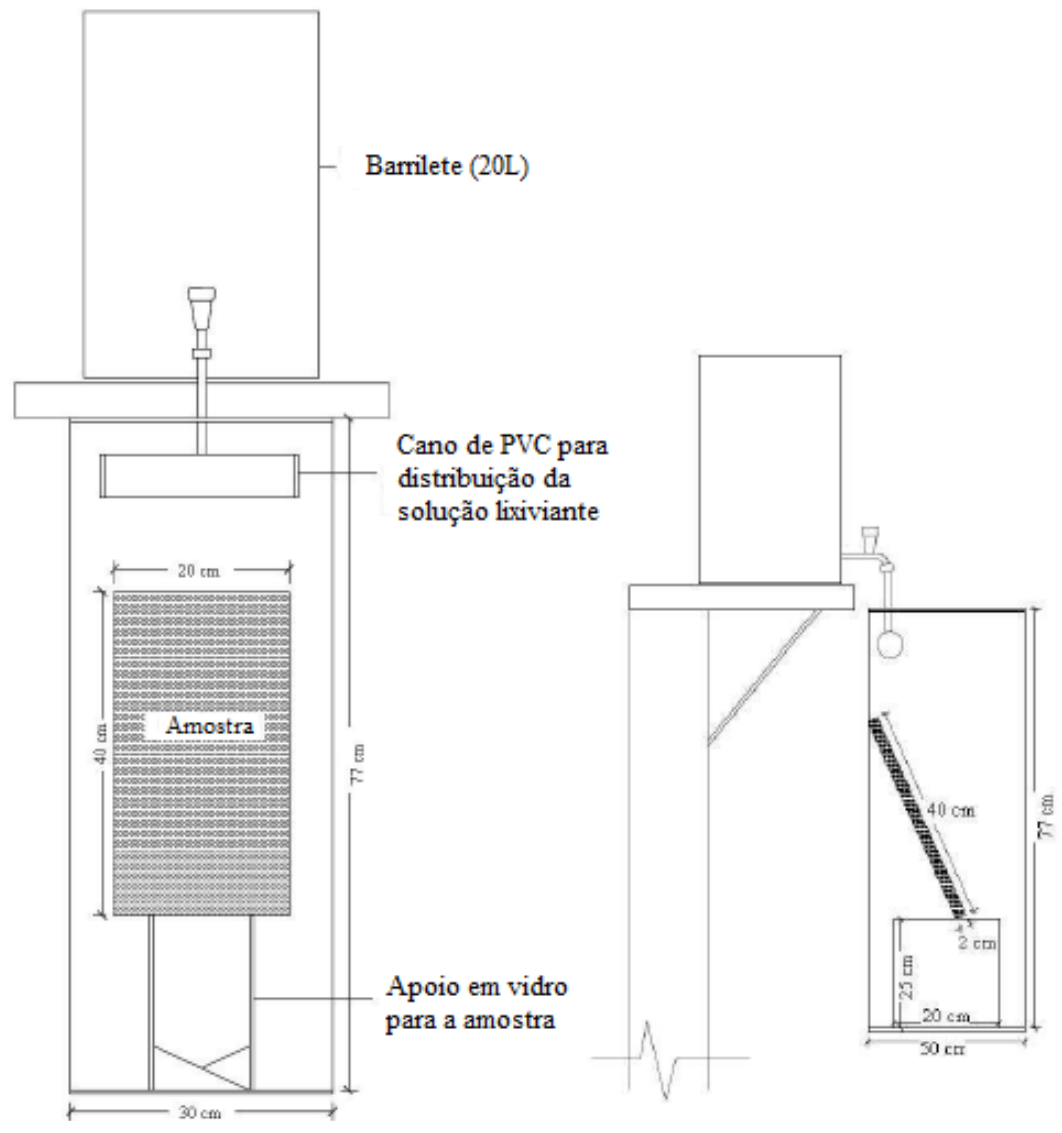


Figura 4 - Teste de lixiviação por irrigação em execução

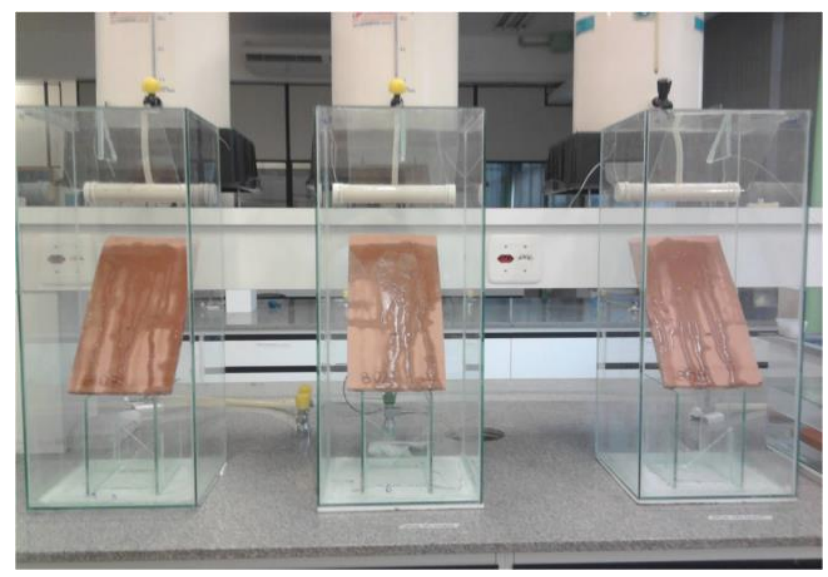

Análise de concentrações de $\mathrm{Cr}$ total - a concentração de $\mathrm{Cr}$ total foi efetuada na cerâmica de referência, sem ser submetida à lixiviação, e nos extratos lixiviados, empregando-se a técnica ICPAES, cujo princípio fundamental consiste na ionização dos elementos a serem analisados pelo plasma indutivo de argônio (GUINÉ, 1998).A técnica permite a determinação da composição química de metais de modo quantitativo, desdepequenos níveis de concentrações (ppm) até níveis de concentração maiores (porcentagem). Conforme os órgãos ambientais licenciadores, a análise deve ser conduzida em laboratórios certificados. Dessa forma, as determinações de $\mathrm{Cr}$ total das amostras dos extratos lixiviados, nos testes de imersão e de irrigação, foram realizadas em um laboratório certificado pela Fundação Estadual de Proteção Ambiental(Fepam), órgão ambiental regulamentador do Estado do Rio Grande do Sul, sob o número 00029/2013. O método empregado pelo laboratório foi o EPA 200.7, e o limite de detecção foi de $0,0007 \mathrm{mg} / \mathrm{L}$.

\section{Produção dos corpos de prova}

Os primeiros ensaios conduzidos para avaliar os testes do método proposto empregaram corpos de prova cerâmicos, conformados nas dimensões propostas. Adotou-se como contaminante o $\mathrm{Cr}_{2} \mathrm{O}_{3}$ na concentração de $0,05 \%$ em relação à massa total de argila. Dois grupos de corpos de prova foram produzidos: corpos de prova de referência, sem óxido de cromo (CP0); e corpos de prova com óxido de cromo (CP1). Para cada grupo foram produzidos 7 corpos de prova, sendo 3 para cada um dos métodos propostos e 1 para análise pelo método da NBR 10005 (ABNT, 2004a).

\section{Apresentação e análise dos resultados}

\section{Concentrações de $\mathrm{Cr}$ total}

A amostra de referência, a cerâmica sem cromo, íntegra, não submetida aos ensaios de lixiviação,apresentou concentração de 11,90 ppm de cromo. Valores nessa ordem de grandeza também foram observados por Weng, Lin e Chiang (2003) e Herek et al.(2012) em cerâmica vermelha.

Os resultados são apresentados na Tabela 2, e o resultado final do teste compreendeu a soma da concentração de $\mathrm{Cr}$ total liberado nos 4 ciclos de lixiviação de cada teste.

As médias de $\mathrm{Cr}$ total detectadas nas soluções provenientes dos testes de imersão e irrigação são apresentadas na Figura 5. Para o teste de imersão observa-se que o lixiviado de CP1 apresentou no $1^{\circ}$ ciclo de ensaio, aos 7 dias, uma concentração aproximadamente 5 vezes maior que a concentração de $\mathrm{Cr}$ detectada no $2^{\circ}$ ciclo, aos 14 dias. A liberação do $\mathrm{Cr}$ diminui ao longo do tempo no teste de imersão, estabilizando-se até o $4^{\circ}$ ciclo. A lixiviação ocorrida ao longo do teste de irrigação é muito menor, com pequena queda na concentração de $\mathrm{Cr}$ ao longo do tempo de ensaio. A análise também indicou que o desvio padrão dos dois testes é muito baixo, o que leva a um baixo coeficiente de variação.

Segundo Sloot (1997), a lixiviação é um processo governado pelo mecanismo de difusão, em que a extração de um elemento de um sólido é proporcional ao tempo de contato entre os dois meios, o que pode explicar as menores concentrações de $\mathrm{Cr}$ nos extratos lixiviados obtidos pelo testede irrigação. 
Figura 5 - Lixiviação do $\mathrm{Cr}$ pelos testes propostos

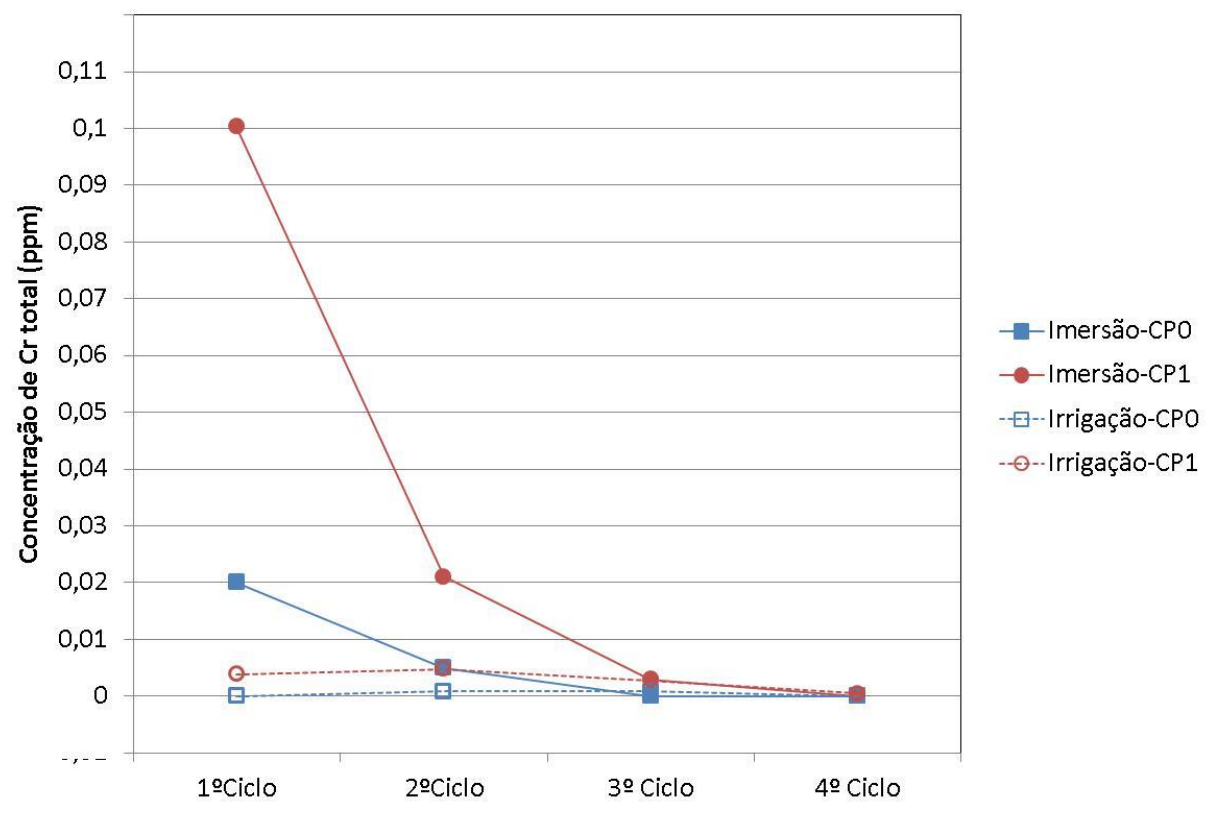

O teste de irrigação foi caracterizado por iniciar a lixiviação do $\mathrm{Cr}$ através da dissolução de componentes da superfície; posteriormente o processo passou a ser governado pelo mecanismo de difusão (SLOOT; DIJKSTRA, 2004; PUREZA, 2004; BASEGIO, 2004). Num primeiro momento, a solução lixiviante solubilizou apenas o $\mathrm{Cr}$ próximo à superfície do corpo de prova. É provável que a absorção da solução lixiviante pelo corpo de prova tenha-se dado através das forças de capilaridade. Sloot e Dijkstra (2004) explicam que na liberação de contaminantes de um monólito, quando em contato com a chuva, o processo que prevalece é a dissolução dos elementos solúveis através da lavagem superficial, e as forças de capilaridade atuam na absorção da solução lixiviante.

O mecanismo de lixiviação ocorrido nos testes de imersão e irrigação pode ser também explicado mediante a comparação com os princípios da norma NEN 7345 (NETHERLANDS..., 1995). Poon e Chen (1999), empregando o teste da norma holandesa, esclarecem que na lixiviaçãoocorre inicialmente uma degradação da superfície da amostra pela ação da solução lixiviante, e o grau da degradação da superfície tende a aumentar com o tempo, fazendo com que a concentração do componente no lixiviado também aumente. Após certo período, a degradação da superfície alcança um estágio de erosão, e a concentração do componente no lixiviado começa a decrescer, obedecendo então à Lei da Difusão. Em função de não haver sido utilizada pressão em nenhum dos ensaios, estima-se que o transporte do $\mathrm{Cr}$ tenha-se dado em todas as direções. Segundo Rosa (2001), a realização de ensaios de lixiviação sem pressão artificial é muito utilizada para resíduos estabilizados considerados perigosos.

$\mathrm{O}$ Cr encontrado no lixiviado do CP0 é explicado por sua existência na cerâmica de referência. Por ser um elemento de elevada solubilidade em $\mathrm{HNO}_{3}$ diluído (SHRIVER; ATKINS; LANGFORD, 1994), o Cr, mesmo presente em baixa concentração no corpo de prova, foi lixiviado e então constatado dentro do limite de detecção da técnica ICP-AES. O comportamento da lixiviação do $\mathrm{Cr}$ no $\mathrm{CP} 0$ pode ser explicado de maneira análoga ao do corpo de prova com $\mathrm{Cr}$ nos testes de lixiviação.

Avaliação do tempo de execução dos ensaios considerando o resultado do teste de imersão, pode-se dizer que, devido à renovação da solução lixiviante, não houve risco de saturação da solução; consequentemente, a lixiviação do $\mathrm{Cr}$ ocorreu durante todo o período de teste. A concentração inicial maior de $\mathrm{Cr}$ no lixiviado foi um indício de que, primeiramente, houve dissolução do $\mathrm{Cr}$ presente na superfície do corpo de prova, sugerindo o movimento daquele a partir da superfície deste. Conforme os ciclos foram avançando, um gradiente de concentração do interior do corpo de prova até a interface da solução lixiviante foi formado, favorecendo então que o $\mathrm{Cr}$ se difundisse através dos poros da cerâmica, que estavam saturados com a solução lixiviante. Por outro lado, com o passar do tempo e a renovação da solução lixiviante, o estado de equilíbrio entre o sólido (corpo de prova) e o líquido (solução lixiviante) foi-se aproximando, 
mais precisamente após o $3^{\circ}$ ciclo. Pôde-se verificar que, após 21 dias, a taxa de lixiviação tendeu a zero. Essa diminuição da taxa de lixiviação pode estar relacionada com a solubilização de um elemento em função do tempo e explicada pela Lei de Fick.

Já no teste de irrigação, devido ao comportamento da lixiviação observado nos dois primeiros ciclos do teste, observa-se que o intervalo de tempo de 6 dias de secagem entre os ciclos de molhagem proporcionou a evaporação da solução lixiviante do corpo de prova e a consequente migração do $\mathrm{Cr}$ para a superfície; no $2^{\circ}$ ciclo de molhagem, houve aumento de concentração de $\mathrm{Cr}$ no lixiviado; no $3^{\circ}$ ciclo foi observado decréscimo na concentração; e no $4^{\circ}$ ciclo, tendência à estabilização. Dessa forma, considera-se que os 28 dias de teste foram suficientes para que ocorresse o processo de difusão.

Com base nos resultados, pode-se considerar o tempo de 28 dias empregado para a execução dos testes desta proposta viável, pois emprega um espaço de tempo já usado rotineiramente no meio técnico do ambiente construído para avaliar outras propriedades de materiais e componentes.

Teste de lixiviação da NBR 10005 (ABNT, 2004a) - em virtude de o elemento de análise adotado neste estudo ser o $\mathrm{Cr}$, os resultados da lixiviação que se referem a esse elemento compreenderam 0,005 ppm para CP0 e 0,023 ppm para CP1. O limite de detecção da técnica de análise adotada é de 0,0007 ppm.
Levando-se em conta que os testes de lixiviação são ferramentas para verificar o impacto ambiental que causaria determinado material quando seus componentes são transferidos para o meio ambiente, a norma brasileira de resíduos sólidos NBR 10004 (ABNT, 2004b) atua no sentido de estabelecer padrões máximos desses componentes no meio ambiente, estabelecendo o limite de 0,05 ppm de $\mathrm{Cr}$ total no extrato lixiviado. Portanto, segundo os resultados apresentados para o teste de lixiviação da NBR 10005 (ABNT, 2004a), bem como os resultados apresentados pelo teste imersão e de irrigação, o corpo de prova com $\mathrm{Cr}$ não extrapola esse limite.

Diferenças entre metodologias - existem várias diferenças entre as metodologias da NBR 10005 (ABNT, 2004a) e as desenvolvidas nesta pesquisa. Tais diferenças se devem ao fato da aplicabilidade dos testes, isto é, a NBR prevê um cenário de disposição final em aterro, e os testes propostos, como método de obtenção de extrato lixiviado de componentes e materiais de construção, preveem cenários de exposição em uso, como chuvas e alagamentos. A Tabela 3 apresenta as diferenças entre o método da NBR 10005 (ABNT, 2004a) e os testes propostos neste trabalho para obtenção de extrato lixiviado.

As diferenças de características entre os testes de lixiviação acentuam as diferenças nos resultados. Tomando como base os resultados do CP1, a Tabela 4 apresenta os valores de concentração de $\mathrm{Cr}$ total obtidos no lixiviado para as três metodologias.

Tabela 3 - Características das metodologias de lixiviação

\begin{tabular}{c|c|c|c|c|c}
\hline $\begin{array}{c}\text { Metodologia } \\
\text { de lixiviação }\end{array}$ & Forma da amostra & $\begin{array}{c}\text { Solução } \\
\text { lixiviante }\end{array}$ & $\begin{array}{c}\text { Característica } \\
\text { do teste }\end{array}$ & $\begin{array}{c}\text { Relação } \\
\text { amostra: } \\
\text { líquido }\end{array}$ & Período do teste \\
\hline $\begin{array}{c}\text { NBR 10005 } \\
\text { (ABNT, } \\
2004 \mathrm{a})\end{array}$ & $\begin{array}{c}\text { Triturada } \\
(<9,5 \mathrm{~mm})\end{array}$ & $\mathrm{pH} 5,0$ & $\begin{array}{c}\text { Estático } \\
\text { sob agitação }\end{array}$ & $1: 20$ & $18 \mathrm{~h}$ \\
\hline $\begin{array}{c}\text { Teste de } \\
\text { irrigação }\end{array}$ & $\begin{array}{c}\text { Bloco sólido } \\
\text { monólito:(40x20x2c } \\
\mathrm{m})\end{array}$ & $\mathrm{pH} 3,0$ & $\begin{array}{c}\text { Dinâmico } \\
\text { sob gotejamento }\end{array}$ & $1: 7$ & $\begin{array}{c}\text { 24hcada } \\
\text { - intervalos de 144h } \\
\text { entre as extrações }\end{array}$ \\
\hline $\begin{array}{c}\text { Teste de } \\
\text { imersão }\end{array}$ & $\begin{array}{c}\text { Bloco sólido } \\
\text { monólito:(40x20x2c } \\
\mathrm{m})\end{array}$ & $\mathrm{pH} 3,0$ & $\begin{array}{c}\text { Dinâmico } \\
\text { sob imersão }\end{array}$ & $1: 7$ & $\begin{array}{c}\text { - 4 extrações de } \\
168 \mathrm{hcada}\end{array}$ \\
\hline
\end{tabular}

Tabela 4 - Concentrações de $\mathrm{Cr}$ total presente no lixiviado do CP1

\begin{tabular}{cc}
\hline Testes de lixiviação & Concentração de Cr (em ppm) \\
\hline NBR 10005 (ABNT, 2004a) & 0,02300 \\
Teste de irrigação & 0,01183 \\
Teste de imersão & 0,12430 \\
\hline
\end{tabular}


O teste de imersão apresentou resultados de concentração total obtida no extrato lixiviado cinco vezes maior do que o obtido pela NBR, mesmo este último apresentando uma relação amostra/líquidomaior do que o teste em questão. No entanto, o pH da solução do teste de imersão é mais agressivo do que o da NBR, bem como o tempo de exposição da amostra, e os ciclos de imersão e secagem parecem auxiliar na migração do Cr para a superfície de contato com a solução. Os resultados da proposta de imersão indicam que este está a favor da segurança. No entanto, o teste de irrigação se mostrou mais brando do que o método da NBR 10005 (ABNT, 2004a), o que indica que uma situação de exposição à chuva ácida seria menos agressivo do que uma situação de alagamento.

\section{Considerações finais}

A presente pesquisa propôs e testou métodos de obtenção de extrato lixiviado para a avaliação ambiental de materiais e componentes de construção civil, principalmente de habitações. Os testes procuraram simular duas condições adversas de exposição de sistemas construtivos por meio da imersão de amostras em solução lixiviante e de irrigação dela sobre a superfície de uma amostra.

A proposta de tamanho do corpo de prova buscou simular um segmento componente construtivo que venha, por exemplo, a ser empregado como piso, vedação ou cobertura. A simulação em escala real não é conveniente, uma vez que deve ser considerado, após a condução do ensaio, o descarte dos volumes de lixiviado com contaminantes. Além disso, tendo em vista o tamanho sugerido para os corpos de prova e adotando-se uma proporção entre volume da amostra e volume da solução lixiviante de $1 / 7$, pode-se afirmar que, proporcionalmente, os métodos propostos consomem menos solução do que o método NBR 10005 (ABNT, 2004a).

A avaliação da montagem e a condução dos métodos de ensaio para obtenção de extrato lixiviado indicam que são métodos facilmente montados, pois, da forma proposta, não requerem materiais nem serviços sofisticados para a produção dos dispositivos. No entanto, com a condução de outras baterias de ensaio e tipos de materiais, talvez ainda sejam necessárias algumas adaptações ou otimizações.

Quanto ao extrato lixiviado, os resultados indicam tendência de comportamento coerente e compatível com os resultados obtidos pelo método NBR 10005 (ABNT, 2004a), sendo o método de imersão mais agressivo do que a referida norma. Em relação a sua viabilidade quanto ao tempo de execução para a obtenção das amostras de extrato lixiviado, o método foi proposto para ser conduzido em um período de resposta que o meio técnico científico já emprega para conduzir outros ensaios, o que provavelmente fará com que esse parâmetro seja considerado aceitável. Além disso, após quatro ciclos de 7 dias de exposição, foi possível observar tendência à estabilização na concentração de $\mathrm{Cr}$ no extrato lixiviado de ambos os testes propostos para compor o método.

\section{Referências}

\section{AMERICAN NUCLEAR SOCIETY. ANS 16.1:}

measurement of the leachability of solidified lowlevel radioactive wastes. Chicago, 2003.

\section{ASSOCIATION FRANÇAISE DE NORMALIZATION. NF X 31-211:}

Caractérisation des déchets: essai de lixiviation d'un déchet solide initialement massif ou généré par un procédé de solidification. Paris, 2012.

\section{ASSOCIAÇÃO BRASILEIRA DE NORMAS}

TÉCNICAS. NBR 10004: resíduos sólidos. Rio de Janeiro, 2004b.

\section{ASSOCIAÇÃO BRASILEIRA DE NORMAS TÉCNICAS. NBR 10005: procedimento para obtenção de extrato lixiviado de resíduos sólidos. Rio de Janeiro, 2004a.}

\section{ASSOCIAÇÃO BRASILEIRA DE NORMAS TÉCNICAS. NBR 10006: procedimento para obtenção de extrato solubilizado de resíduos sólidos. Rio de Janeiro, 2004c.}

BASEGIO, T. M. Imobilização do Íon Cromo Oriundo de Cinzas de Incineração de Serragem de Couro em Corpos Cerâmicos Vitrificados Porto Alegre, 2004. 134 f. Tese (Doutorado em Engenharia Civil) - Programa de Pós-Graduação em Engenharia de Minas, Metalúrgica e de Materiais, Universidade Federal do Rio Grande do Sul, Porto Alegre, 2004.

BREHM, F. A. et al. Análise da Estabilização Por Solidificação de Lodo de Fosfatização em Matrizes de Cimento Portland e de Cerâmica Vermelha Para a Utilização na Construção Civil. Ambiente Construído, Porto Alegre, v. 13, n. 2, p. 15-27, abr./jun. 2013.

BRITO, A. L. F. Protocolo de Avaliação de Materiais Resultantes da Estabilização Por Solidificação de Resíduos. Florianópolis, 2007. 179 f. Tese (Doutorado em Engenharia Ambiental) - Programa de Pós-Graduação em Engenharia Ambiental, Universidade Federal de Santa Catarina, Florianópolis, 2007. 
BRITO, A. L. F.; SOARES, S. R.. Avaliação da Integridade e da Retenção de Metais Pesados em Materiais Estabilizados Por Solidificação. Engenharia Sanitária e Ambiental, Rio de Janeiro, v. 14, n. 1, p. 39-48, jan./mar. 2009.

CAUDURO, F.; ROBERTO, S. Avaliação Comparativa de Testes de Lixiviação de Resíduos Sólidos. In: CONGRESO INTERAMERICANO DE INGENIERIA SANITARIA Y AMBIENTAL, 28., Cancun, 2002. Anais...Cancun: AIDIS, 2002.

DEUTSCHES INSTITUT FÜR NORMUNG. DIN 38414-4: german standard methods for the examination of water, waste water and sludge; sludge and sediments (group S); determination of leachability by water. Berlin, 1984.

EIKELBOOM, R. T.; RUWIEL, E.; GOUMANS J.J.J.M. The Building Materials Decree: an example of a Dutchregulation based on the potential impact ofmaterials on the environment. Waste Management, v. 21, n. 3, p. 295-302, 2001.

GOMES, G. M. F. Redução do Impacto da Escória de Obtenção do Chumbo Por Via Secundária. 2006. 146 f. Dissertação (Mestrado em Engenharia Química) - Programama de Pós Graduação em Engenharia Química, Univerisidade Federal do Rio Grande do Sul, Porto Alegre, 2006.

GUINÉ, M. F. Espectrometria de

EmissãoAtômicaCom Plasma

AcopladoIndutivamente: ICP-AES. Piracicaba: CPG-CENA-USP, 1998.

HEREK, L. C. S. et al. Characterization of Ceramic Bricks Incorporated With Textile Laundry Sludge. Ceramic International, v. 38, p.951-959, 2012.

JONH, V. M.; ÂNGULO, S. C. Requisitos Para Execução de Aterros de Resíduos de Construção e Demolição. Boletim Técnico, São Paulo, 2006, Disponível em:

<http://publicacoes.pcc.usp.br/PDF/BTs_Petreche/ BT436\%20-\%20Angulo.pdf $>$. Acessoem: 25 nov. 2011.

NETHERLANDS NORMALIZATIONN. NEN

7345: determination of release of inorganic constituents from construction material and stabilized waste products. Netherlands, 1995.

POON, C. S.; CHEN, Z. Q. Comparison of the Characteristics of Flow-Through and Flow-Around Leaching Tests of Solidified Heavy Metal Wastes. Chemosphere, Amsterdam, v. 38, n 3. p. 663-680, 1999.
PUREZA, J. C. C. Utilização de Resíduos Industriais de Baixa Granulometria em Massas Cerâmicas de Argila Vermelha: aspectos tecnológicos e ambientais.Porto Alegre, 2004. 148f. Dissertação (Mestrado em Engenharia Civil) - Programa de Pós-Graduação em Engenharia de Minas, Metalúrgica e de Materiais, Universidade Federal do Rio Grande do Sul, Porto Alegre, 2004.

ROSA, M. A. Caracterização da Incorporação da escória de Aço Inoxidável em Materiais Cerâmicos Quanto a Imobilização de Cromo. Porto Alegre, 2001. 150 f. Dissertação (Mestrado em Engenharia Civil) - Programa de PósGraduação em Engenharia de Minas, Metalúrgica e de Materiais, Universidade Federal do Rio Grande do Sul, Porto Alegre, 2001.

SHRIVER, D. F.; ATKINS, P. W.; LANGFORD, C. H. Inorganic Chemistry. New York: Oxford, 1994.

SLOOT, H. Environmental Efficiency of Immobilization Techniques For Wastes in Relation to Utilization and Disposal. In: ACTES DU CONGRÈS INTERNATIONAL SUR LES PROCÉDÉS DE SOLIDIFICATION ET DE STABILISATION DES DÉCHETS, Grenoble, 1997. Anais... Grenoble: Société Alpine de Publications, 1997.

SLOOT, H.; DIJKSTRA, J. J. Development of Horizontally Standardized Leaching Tests for Construction Materials: a meterial based or release based approach? Identical leaching mechanisms for different leaching materials, ENC: Energy Comission of the Netherlands -C-04-060, Petten, jun. 2004.

\section{UNITED STATES ENVIRONMENTAL} PROTECTION AGENCY. Method 1311 TCLP: toxicity characteristic leaching procedure. test methods for evaluating solid waste. Washington DC, 1992.

\section{UNITED STATES ENVIRONMENTAL} PROTECTION AGENCY. Method 1320 MEP: multiple extraction procedure. Washington DC, 1986.

\section{UNITED STATES ENVIRONMENTAL} PROTECTION AGENCY. Method 1310B EP: extraction procedure (EP) toxicity test method and structural integrity test. Washington DC, 2004.

VOLLPRACT, A.; BRAMESHUBER, W. Investigations on the Leaching Behavior of Irrigated Constructions Elements.Environment Science and Pollution, v. 17, p. 1177-1182, 2010. 
WENG, C-H.; LIN, D-F.; CHIANG, P-C.

Utilization of Sludge as Brick Materials.

Advances in Environmental Research,v. 7, n. 3, p. $679-685,2003$.

\section{Agradecimentos}

Esta pesquisa foi financiada com recursos da Financiadora de Estudos e Projetos(Finep), através da Chamada Pública Saneamento Ambiental e Habitação 07/2009 (Rede Inovatec).

Marlova Piva Kulakowski

Programa de Pós-Graduação em Engenharia Civil, Unidade Acadêmica de Pesquisa e Pós-Graduação | Universidade do Vale do Rio dos Sinos | AV. Unisinos, 950, Cristo Rei | São Leopoldo - RS - Brasil | CEP 93022-000 | Tel.: (51) 3591-1294 | E-mail: marlovak@unisinos.br

\section{Feliciane Andrade Brehm}

Programa de Pós-Graduação em Engenharia Civil, Unidade Acadêmica de Pesquisa e Pós-Graduação | Universidade do Vale do Rio dos Sinos | Tel.: (51) 3591-1100 Ramal 1662 |

E-mail: felicianeb@unisinos.br

\section{Claudio de Souza Kazmierczak}

Programa de Pós-Graduação em Engenharia Civil, Unidade Acadêmica de Pesquisa e Pós-Graduação | Universidade do Vale do Rio dos Sinos | Tel.: (51) 3591-1264 | E-mail: claudiok@unisinos.br

\section{Mariele Lunkes}

Programa de Pós-Graduação em Engenharia Civil, Unidade Acadêmica de Pesquisa e Pós-Graduação | Universidade do Vale do Rio dos Sinos | Tel.: (51) 3590-8245 | E-mail: m_lunkes@hotmail.com

\section{Revista Ambiente Construído}

Associação Nacional de Tecnologia do Ambiente Construído

Av. Osvaldo Aranha, $99-3^{\circ}$ andar, Centro

Porto Alegre - RS - Brasil

CEP $90035-190$

Telefone: +55 (51) 3308-4084

Fax: +55 (51) 3308-4054

www.seer.ufrgs.br/ambienteconstruido

E-mail: ambienteconstruido@ufrgs.br 